N $71-36494$ NASA TM X-67942

\&
$\frac{1}{0}$
$\frac{1}{x}$
$\frac{\pi}{2}$

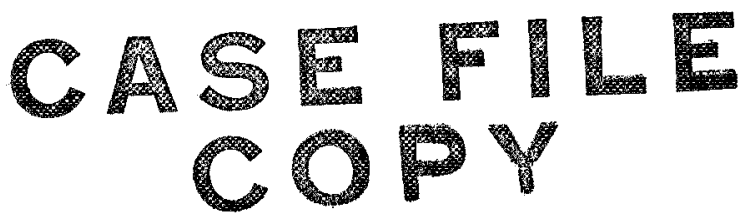

\title{
AEROSPACE RELIABILITY APPLIED TO BIOMEDICINE
}

by V.R. Lalli and D. J. Vargo

Lewis Research Center

Cleveland, Ohio

TECHNICAL PAPER prepared for presentation at

Electronic Aerospace Systems Convention sponsored

by the Institute of Electrical and Electronic Engineers

Washington, D.C., October 6-8, 1971 


\title{
AEROSPACE RELIABILITY APPLIED TO BIOMEDICINE
}

\author{
by V. R. Lalli and D. J. Vargo \\ Lewis Research Center
}

\begin{abstract}
This paper presents an analysis that indicates that the Reliability and Quality Assurance methodology selected by NASA to minimize failures in aerospace equipment can be applied directly to biomedical devices to improve hospital equipment reliability. The Space Electric Rocket Test project is used as an example of NASA application of Reliability and Quality Assurance (R\&QA) methods. By analogy a comparison is made to show how these same methods can be used in the development of transducers, instrumentation and complex systems for use in medicine.
\end{abstract}

\section{INTRODUCTION}

Both NASA and the biomedical industry are involved in the design and operation of important and complex equipment. Furthermore, these systems must operate accurately and reliably. Failure can cause economic loss; even worse, it can result in the loss of human life. NASA has developed an extensive reliability and quality assurance (R\&QA) methodology. It is possible that this methodology could be used as the basis for an appropriate $R \& Q A$ program for medical instrumentation. Such a program should be aimed at improving equipment performance, reducing failures, and $a b-$ solutely minimizing risks of personal injury or death.

The bioinstrumentation industry today is in a situation in some ways comparable to the early days of the space program. NASA was faced with the task of adapting, advancing and rapidly applying complex technologies to accomplish space-flight programs. Historically, the biomedical industry has been characterized by the relatively leisurely application of modest 
incremental advances of technology developed by working with animal subjects. This slow pace in the past allowed extended investigation by both manufacturers and practicing doctors on the benefits and effects of incorporation of these advances. Recently, however, large and rapid changes have been occurring in medical instrumentation; the increased use of medical electronic apparatus in intensive care hospital facilities represents one such dramatic change in biomedical technology.

That the application of rapid changes in technology can lead to serious difficulties, however, can easily be established. A recent survey, (ref. 1) of medical electronic gear in 12 Detroit-area hospitals disclosed many disturbing findings. Among its findings are:

1. Few pieces of equipment are properly maintained;

2. Simple calibrations like adjusting a potentiometer and simple adjustments like focusing an oscilloscope are not made;

3. Dust is allowed to build up inside chassis, causing components to overheat;

4. Few defibrillators accurately produce the amount of energy they are supposed to;

5. Most monitoring oscilloscopes and electrocardiographs (ECG) have substandard frequency response;

In addition, medical equipment was found to contain the following defects:

6. Low quality parts were used in construction;

7. Planning in the placement of equipment was poor;

8. Poor grounding was found in some cases;

9. Leakage currents were often in excess of the $10 \mu \mathrm{A}$ level which has been recommended by the Veterans Administration and others;

10. Transient voltage or current surges often occurred when monitors were turned on;

11. Equipment was not protected adequately from its operating environment;

12. Significant waveshape changes occurred in the output equipment;

13. Equipment was misused by being operated by untrained personnel; Some of these findings are illustrated in figure 1. To overcome similar 
problems in achieving highly dependable equipment performance, NASA developed an extensive methodology for improving, maintaining and verifying design reliability and product quality of space program hardware. That this methodology works can be seen from a representative improvement in launch vehicles performance. In 1959, only 57 percent of the launches met test objectives. In 1967, 93 percent fully met all test objectives and these later launch vehicles were of larger size and greater complexity than those of 8 years earlier.

The purpose of this paper is to examine illustrative parts of the methodology developed by NASA to achieve equipment reliability. There are many obvious differences between the space and biomedical fields, and much that is done to achieve reliability of space equipment is not directly applicable in the biomedical area. Much of the methodology should be of value, however, and its application should solve many equipment performance - use problems.

This space related methodology for dependable equipment performance is based on the careful application of two existing engineering disciplines: (1) reliability, and (2) quality assurance. The methods selected for use in these disciplines are those found to be effective in the improvement of product performance. Reliability engineering is concerned with design and testing tasks in product development to ensure that the product is properly designed to perform the assigned task without failure. Quality assurance is concerned with various control methods and qualification testing to ensure that the product delivered is manufactured as designed.

This may sound like an involved way of saying "be sure to use good engineering practice for each product. " Todays complex equipment and systems, however, demand the assignment of specific responsibility for the R\&QA tasks and require the application of proven techniques and methods. The fact is that biomedical product performance problems do exist; the industry must do something about them. 


\section{RELIABILITY}

We will now consider first Reliability and then Quality Assurance.

Reliability engineering consists of two fundamental tasks: design studies and product tests. The subelements under design studies are as follows:

Design Criteria

Design Practices

Design Review

Each of these subelements is important in achieving a reliable product with reliability engineered into the product as it is designed and tested.

\section{Design Criteria}

A product idea is conceived, and the concept includes general ideas on basic functions and performance. Design criteria must be established before the actual design is undertaken; some design criteria are listed below:

1. Functional specifications;

2. Operational requirements;

3. Environmental specifications;

4. Parts and materials selection procedures;

5. Codes, standards, and specifications;

6. Structural design factors;

7. Electromagnetic compatibility.

Most of these criteria are self explanatory, however, if desired, additional information is found in existing literature (refs. 2 to 8 ).

Referring to parts and materials selection procedures, one of the problems identified in the Detroit area hospitals' electronic medical equipment survey was poor parts. One example given was leaking electrolyte from a faulty capacitor causing a resistor in an ECG to short out. NASA's way of eliminating weak parts is to require that a specific detailed procedure for selecting, qualifying and screening parts, and materials be established. When possible, we use only those parts which are given in 
Preferred Parts List (ref.3). Furthermore, it is required that all parts be subjected to appropriate types of screening test. Screening tests are, of course, different for each class of part and are based on both engineering judgment and experience. They are directly related to expected equipment performance, operating life and environment. Representative screening tests might be:

- X-ray or vidicon examination to determine contamination and internal configuration;

- Ten complete temperature cycles to temperature extremes, representative of worst case environment; measure performance parameters before the first cycle and after last cycle;

- Burn-in (full operation) under rated conditions; check performance parameters four times at selected intervals to determine the trend of parameter shifting;

The reported Electrolyte leaking from a capacitor could also have been caused by insufficient part derating. Electrolytic capacitors normally have a rated voltage and temperature specified by the manufacturer. Other factors being equal, component-part failure rates increase with stress applied in operation. Furthermore, even the best parts when operated at maximum-rated stress levels do not have sufficiently low failure rates to give highly reliable products. It has been established that, if the voltage and temperature stresses on an electrolytic capacitor are reduced by a factor of 0.7 , failure frequency can be reduced by two or three orders of magnitude. Therefore, as a design criteria, all electronic piece parts should be derated according to those parameters obtained either from existing literature or by testing (refs. 8 and 9).

The environment that a product has to perform in, plays an important role in determining design criteria. Space products must contend with the harmful effects of such things as vibration, shock, temperature, salt spray, fungus and vacuum. Biomedical products would see things like vibration, shock, temperature, fluid spills, inexperienced operating personnel, dust and dirt in their hospital environment. Design criteria must reflect the expected environment. 
Considerations such as these lead to the design criteria for reliability. These criteria establish the degree of conservatism built into the product. The reliability engineer has the duty of making certain that accurate and complete data are available on which to base the design criteria.

\section{Design Practices}

Good design practices set many of the constraints for a transfer device arrangement. A transfer device is a group of parts which accepts an input variable, changes the variable form and transfers the variable to a second location for further use. Reliability analysis is very important in developing proper design practices for the product transfer device arrangement. The first step in this analysis is to develop a transfer device diagram. Using probability methods and the known or predicted generic failure rate of the piece parts combined in transfer device arrangements, the probability of success or reliability is calculated. However, neither the numbers calculated nor the failure frequency functions used are necessarily im portant at this point. What is important is the relative standing of the various transfer devices, for this establishes a priority listing of items to be worked on for improved reliability. A study of these standings is used to develop reliability related questions, design practices, representative examples of which are listed below:

1. Are the minimum number of different parts being used?

2. Is that new transfer device with the high failure rate really necessary?

3. For the high failure rate items, is redesign or redundancy the better approach, or should both be used?

4. Is the design in suitable form for isolating and analyzing test failures?

Redundancy is the use of two or more sets of selected transfer devices to perform the same transfer. In some cases, it is desirable and should be used; in others, it can cause more trouble than it cures. Recognition 
of these conditions and the trade-offs required to make a reliable product is the province of the reliability engineer. Examination of the design for proper design practice is a continuous part of the design process.

\section{Design Review}

Design review is conducted in a series of formalized meetings to uncover and resolve hidden weaknesses in a product transfer device arrangement. These reviews are usually held during three phases of the design process: conceptual, intermediate, and final design reviews.

During the conceptual design review, the basic transfer devices of the product are examined. Following the preliminary design review, piece parts are selected, specifications are drafted and preliminary drawings are prepared.

The intermediate design review is held to examine design data and schematics to establish that the product can do the required job and that the transfer devices selected satisfy the design criteria. Now the design is ready for a failure modes, effects, and corrective action analysis (FMECA). Here the reliability engineer asks the questions "What if . . . ?" and attempts to figure out specifically what the product will do if certain modes of failure should happen. The design is examined in considerable detail with the following questions in mind:

1. How can a part or component fail?

2. What effect does this failure mode have on product performance?

3. How critical is this effect?

4. Can the failure mode be obviated?

5. When is the last time that this failure mode is tested?

As an example of how FMECA is undertaken, consider a thrustor-power conditioner block diagram as shown in figure 2. There are three subsystems in this figure: (1) thrustor, (2) neutralizer, and (3) power conditioning. In the thrustor subsystem, the anode supply, $V_{4}$, and the cathode keeper supply, $\mathrm{V}_{10}$, were originally voltage controlled supplies (refs. 10 to 12). The failure mode question was asked: "What happens if the 
accelerator $V_{6}$ arcs to some other electrode? ${ }^{p i}$ Since ions are present, more are being generated and not being removed, it is very likely that the slope of the discharge Volt Ampere (VI) curve will go negative. If it does and there are fixed voltages on $\mathrm{V}_{4}$ and $\mathrm{V}_{10}$, their currents would only be limited by either the number of ions available or the supply resistances. For voltage controlled supplies, current surges could reach failure levels very quickly. This possibility was, of course, totally unacceptable and was avoided by obtaining a VI curve for these supplies tailored to their loads: high starting voltage, constant voltage in the operating discharge region and current limited beyond this region.

This is a real life example. The design existed and was modified as the result of FMECA analysis. As design changes from such analyses are incorporated into a product, the product reliability is substantially improved.

Failure mode data also provides guide lines for setting product tests specifications. Each failure mode should be examined during some phase of the product's testing. All critical failure modes (modes affecting patient safety) must be tested.

The final design review goes over all of the transfer devices to make sure that no failure modes have been missed (individually or collectively) and that the final hardware configuration has not altered the intent of the design as established during the preliminary and intermediate design review.

Consider the case where a molded three prong power cord has been selected to transfer power from a three prong wall receptacle to an electrocardiograph. During final design review, the question must be asked, "What if the ground wire breaks?" There is considerable evidence to show that patient safety is sacrificed (refs. 13 to 15). The detailed design properly used a three-wire power cord but no provisions were made to check the continuity of the third ground wire. To correct this situation, the power cord could be made out of clear plastic insulation and the user instructed to check the ground wire for opens with a visual inspection prior to each use of the electrocardiograph. Better still, a low current 
ground wire continuity indicator could be placed on the instruments front panel and the user instructed never to use an electrocardiograph when this light is out (or a fail safe interlock could be provided, etc.). It would be tolerable to lose a measurement but not to electrocute a patient accidentally. It is to uncover deficiencies like this that a final reliability related design review is held. This too, by the way, is not a hypothetical case. A finding of the Detroit Survey was that ${ }^{\prime \prime} \mathrm{X}$-ray reveals broken ground wire in electrocardiograph ${ }^{7}$ molded plugs."

The product tests task under reliability engineering is heavily concerned with design evaluation through careful evaluation testing. A breadboard model of the product is usually built to verify that the basic transfer device arrangement is capable of meeting design criteria. The product testing that is conducted on the breadboard model is the first step in design evaluation. This testing is usually called functional testing and consists of the following types:

1. Design criteria;

2. Specification range;

3. Worst case stress analysis;

4. Tests for marginality.

The functional tests prove that the system will work as designed. Those tests are conducted for nominal conditions, over the range of input and output variables and under worst case electrical and thermal conditions for which the product should perform properly (ref. 9). After this is successfully accomplished, the variables are extended (raised and/or lowered) usually \pm 10 percent to see if a slightly out of specification variable will cause marginal product performance.

When a breadboard product has passed functional testing and comes through the final design review, prototype products can be fabricated. These models are usually made in an experimental shop to get the product records ready for production. The new product is now ready for more stringent design evaluation testing. Functional tests as described above are repeated; additional representative tests for NASA products are listed along with comparable tests for biomedical products: 
NASA
$\left.\begin{array}{l}\text { 1. Vibration } \\ \text { 2. Thermal } \\ \text { 3. Pressure }\end{array}\right\} \begin{aligned} & \text { Preferably } \\ & \text { combined }\end{aligned}$
4. Shock
5. Acceleration
6. Electromagnetic compatibility
7. Rain, sand, and fungus

Proposed Biomedical $\left\{\begin{array}{l}\text { 1. Vibration } \\ \text { 2. Thermal }\end{array}\right.$

3. Shock

4. Electromagnetic compatibility

5. Corrosive solution

6. Dust and dirt

7. Operation by inexperienced people

During environmental testing, the product is operated in an analogue of the environments it will experience in service. Qualifying a product for use on a spacecraft is often done by advanced stress testing (refs. 7 and 16). Advanced stress testing subjects the equipment to environmental conditions more severe than will be encountered in service. The advanced stress testing is carefully planned to provide predictive performance information. Selecting the stress to be used, planning the combinations thereof and the increased test levels tends to identify design deficiencies with shorter waiting periods without affecting the failure modes.

If at all possible, the environmental tests should be conducted under combined conditions equivalent to those the product will see in service. Equipment like power conditioning supplies used on payloads or launch vehicles, for example, is subjected to launch vibration, temperature, and ascent depressurization all in one test. These tests were designed so that combined factors were applied as they would occur in service.

The Detroit Survey found that in a typical hospital environment, saline solution could be spilled onto equipment causing corrosion and in some cases electrical shorting. The environment also saw dust build-up inside chassis, causing components to overheat and fail. Both of these environmental conditions could have been represented by environmental testing, and designs corrected to work reliably in this environment. Each product intended for hospital use with humans should be subjected to environmental testing which fully reflects its end use service. True, testing may increase the cost of a product but guaranteed no-hazard and reliable performance will most certainly make a premium price acceptable. 
The next phase in testing is to show that the product has sufficient life expectancy for anticipated service. Life testing can be broken up into two categories:

1. Sequential acceptance;

2. Exhibited mean-time-between-failures (MTBF)

Sequential acceptance tests help an ethical producer be sure that a product lot does fully meet design criteria; it protects the consumer from the purchase of a defective product (ref.16). Test constraints can be mutually established or specified by a manufacturer for review by his customer. A product lot is either accepted, continued on test or rejected based on the failure-time performance during this testing。

The exhibited MTBF test is a life test designed to determine product "Wear out" time by probability methods (ref. 17). Life tests consist of operating a product in a typical service environment to determine how long it will operate properly. The operation may be either with or without maintenance depending on the expected operating conditions. A power conditioner for an electric rocket, for example, after reliability engineering, was life tested for more than 7000-hours maintenance free. The life test results supported the engineering prediction that electric rockets were ready for long-term space flight tests.

The Detroit Cardiac Care Survey also found that aging defibrillators do not have proper output waveshapes or energy, and that most monitoring scopes and electrocardiographs have substandard frequency response. Such design deficiencies can be uncovered during MTBF life testing. If a product is placed on life test and operated continuously, initial and regularly repeated detailed performance testing will disclose aging trends. These can be interpreted into predictive curves and reflected in either design approvals or design changes or in use specifications.

To summarize, design problems are held to a minimum by building products from tested parts, transfer devices, subsystems, and from tested systems all interacting together. If something fails during any of this testing, the failure must be carefully studied to define the exact cause. If the failure discloses a design deficiency, the design is changed to preclude such 
failures and appropriate portions of the design evaluation are repeated to verify that the failure mode has been eliminated.

As a part of the test program, there is much to be learned from a careful study of each failure. Failure reporting, analysis and corrective action is one of the important controls used by Quality Assurance as will be explained in the next section. Reliability engineering is also concerned about each failure report as it relates to three important areas:

1. Does this failure exhibit a design deficiency?

2. What parts failed and why?

3. What effect does this failure have on the products exhibited MTBF? An example of data produced by product failure analysis is a specific failure that occurred when a power conditioning subsystem was being subjected to simulated arc testing (see fig. 2). When an arc was applied from $V_{5}$ to $\mathrm{V}_{6}$, a sudden failure occurred in the $\mathrm{V}_{6}$ circuit. A high voltage capacitor $(0.1 \mu \mathrm{fd}, 600 \mathrm{~V})$ shunting the $\mathrm{V}_{6}$ current telemetry resistor had cracked open. The failure mode was electrical transients overstressing the capacitor during the arc. The failure analysis determined that the design was deficient in the capacitors rated voltage was too low for arc transient conditions and an RF bypass was not included. The design was appropriately modified. When the prototype product successfully completes design evaluation, final drawing and process specifications are prepared. The first few products made by the production department are carefully examined and exhaustively tested for formal qualification of both the product and the production facility. When all of these tests have been successfully completed, the product is finally ready for production, sale and public use. The task assigned to Quality Assurance is that of ensuring that production units are made in full accordance with the design and all specifications.

\section{QUALITY ASSURANCE}

The best designed product is only as good as the people and materials finally used to make it. Quality assurance engineers participate in the task of determining that people with the required skills and materials of the 
specified quality are used to build a product. Quality assurance engineering consists of two basic parts, Control and Test. Some of the elements under Control are listed below:

1. Specification review;

2. Failure analysis and corrective action;

3. Flight status review.

Each of the above plays an important part in assuring that a product is built as specified. Even though some may appear redundant, harsh experience has shown that all of the steps are required. Consider first the task of specification review.

\section{Specification Review}

All components for the new product must either be fabricated in-house or purchased. Specifications explain just what is required in each component in either case. Some of the usual detailed tasks accomplished by quality assurance engineers in this control activity are listed below:

1. Drawing review;

2. Configuration review;

3. Procurement document review;

4. Vendor survey;

5. Fabricated article review;

6. Component identification system;

7. Preservation, packaging, handling, storage, and shipping review;

8. Training and certification of personnel

These detailed tasks are either self-explanitory or have been covered well in existing literature (refs. 3,18 to 20 ).

It is important that specifications be written as completely and precisely as possible. Incomplete specifications can cause much difficulty as the following example will illustrate. Open-to-vacuum power conditioning equipment was manifesting a serious internal arcing problem. This arc is illustrated in figure 3. Various environmental tests were made to determine the exact cause (ref. 11), although outgassing was a 
number one suspect. The outgassing specifications required that materials used in the power conditioners have (in general terms): (1) low volatile content, (2) rapid release of volatiles, and (3) low long-term outgassing rates. A vacuum tank pressure $<1 \times 10^{-5}$ torr before startup was also specified. Detailed quality assurance tests (fig. 4) determined that the power conditioning box pressure was about 2 decades higher than the tank pressure. The power conditioning box pressure before startup was subsequently specified and a maximum limit given for outgassing after bakeout, which corrected this particular problem.

Failure Analysis and Corrective Action

When a failure occurs during test, an important data point for product improvement has been generated. Each failure should be analyzed to identify the specific cause and chain of events. The analysis may uncover a subtle design deficiency. Proper corrective action can then be taken to eliminate the deficiency. Unfortunately, many product failures result in a "quick fix" without detailed analysis and testing is resumed without correction of the basic defect. Design and manufacturing techniques are not perfect; mistakes, errors, and omissions will cause failures. If each failure receives a closed-loop analysis and corrective action, future products performance will be greatly improved.

The problem of internal arcing in open-to-vacuum power conditioning equipment discussed above can also be used to illustrate that failure analysis is not fool proof. Outgassing of the power conditioning equipment was brought to acceptable levels by bakeout and increasing the venting rate, but some internal arcing failures continued. Several other failure modes were investigated: magnetic fields, corona and electric fields (ref. 11), but failures for internal arcing still persisted. Conformal coating and aluminized insulating barriers were finally added to reinforce the vacuum insulation. These two design changes solved the problem. The final flight power conditioner with conformally coated circuit boards and aluminized insulating barriers installed is shown in figure 5 . The general problem of 
arcing in high voltage circuits in vacuum is by no means completely solved, by the way, and further research is underway to better understand why vacuum is a weak insulator under certain conditions.

Failure analysis in biomedical equipment would have equal significance and should be conducted in the same closed-loop manner to improve in-hospital performance of the equipment.

\section{Flight Status Review}

It is a NASA policy to fully verify the flight readiness of flight hardware as a means of providing assurance of mission success. The detailed control task accomplished by quality assurance engineers in this activity is primarily in the area of data review. A flight component is considered to be flight ready only if the criteria listed below are met:

1. Fabricated to latest released specifications;

2. Meets all test requirements;

3. Date of fabrication, source, serial number, and history identified;

4. History does not contain repetitive repair, rework, or modifications;

5. Life limited equipment identified;

6. History of stable operation without test anomalies;

7. Each failure has been analyzed with corrective action to preclude recurrence;

8. Each corrective action has been inspected and tested to assure performance;

9. Condition is not degraded by handling or storage;

10. Replacement components handled like flight items;

11. Launch site activities are carefully planned to maintain readiness

Flight readiness status in aerospace terms is not clearly comparable on a direct one-to-one basis to biomedical equipment use, but the eleven criteria given above illustrate the care-before-use philosophy of quality assurance. This same philosophy expressed in concrete well-planned control activity is obviously needed in equipment for use on human patients. 
The problems of productive, informative equipment use and human safety are shared by the equipment manufacturer and the using medical facility. It seems obvious, however, that an extensive "system planning" activity must be undertaken to insure that rooms full of equipment safely and reliably perform the many interrelated functions intended. This critically necessary function is not now being performed.

The second part of quality assurance consists of Test with the following subdivisions:

1. Inspection;

2. Acceptance;

3. Operational.

\section{Inspection}

Inspection of all components that go into a product is a necessary control function and produces data important to the quality assurance engineer. All components must be made in the same manner as those subjected to detailed testing if consistent results are to be obtained. Inspection must be thor ough, and critical parameters must be identified for special attention. Component specifications must be consistently checked against and enforced. Skilled, experienced, and capable craftsmen are required for the inspection function. Inspection instructions must be supplemented with experience and often extensive training if effective quality assurance through inspection is going to be accomplished.

\section{Acceptance}

Customer reliance on the manufacturer's inspection alone to insure proper product performance is not good practice. Rigorous acceptance tests are important to help insure performance. These acceptance tests operate the product in an environment analogous to the end use application. To illustrate the need for thorough acceptance testing, consider a representative transformer problem. 
Our old friend the open-to-vacuum power conditioner was being cor ona tested. Corona activity was observed in the $\mathrm{V}_{4}$ supply. Investigation showed that the output transformer in the $V_{4}$ supply, although manufactured to the qualified open-to-vacuum transformer specifications, was generating a corona in the vicinity of the high voltage winding. Figure 6 shows the open-to-vacuum transformer construction details and the region in which 500 picocoulombs of corona was occurring. This was a potential failure cause that had to be eliminated; one internal arc could fail a power conditioner. The judicious use of acceptance testing detected the improperly assembled transformer, and prevented it from being installed in the flight power conditioner.

\section{Operational}

After the components have been through their individual acceptance tests, they are assembled and finally placed into the spacecraft. Each subsystem is tested. When the subsystem tests are completed satisfactorily, a combined systems test is conducted with all subsystems being required to operate while interacting with each other under simulated flight conditions. Figure 7 shows a typical operational test of an electric rocket spacecraft. Integrated systems testing provides the opportunity to fully assess the operation of the completely equipped spacecraft under as many as possible of the various environmental conditions and operational modes which would be encountered throughout the planned mission.

At the launch site, the subsystem level tests are repeated to determine whether any damage or degradation has occurred during transportation and to verify that the flight hardware is compatible with the ground-support equipment. Finally, the spacecraft is given a final checkout on the launch pad.

Subsequent to launch and during flight, all data from the flight are evaluated to ascertain whether the subsystems performed as predicted and whether any anomalies occurred. Figure 8 shows a typical flight control center for an electric rocket spacecraft. 


\section{CONCLUDING REMARKS}

The methodology described briefly in this report is in no sense a "final" solution to all equipment performance problems. The methodology must be prevented from generating a paper blizzard because all the things that are discovered must be documented and communicated to others in the process of precluding a recurrence. It is important to keep the paper work simple, encourage simple language and short forms. Paper cannot replace sound, simple engineering evaluation and judgment. The methodology does serve to reduce very markedly the frequency of human or material failures, but obviously, it will not completely eliminate them. Also, the system can be costly, sometimes 10 to 15 percent of the equipments cost, but it can save much more.

It is not easy to achieve reliability; it results from intentional effort not by accident. Simple reminders of some of the things that are required to achieve reliable products are listed below:

1. Reliability is designed into a product through conscious effort on the part of qualified individuals.

2. Product design must provide for adequate reliability margins.

3. Testing is a powerful tool to evaluate a product's design performance. The equipment and facilities required to perform full-system environmental tests are usually found to be well worth the cost. The product must provide for necessary exhaustive testing.

4. Test specifications are important in achieving a reliable product and must be considered as part of the design process.

5. It is essential to monitor and control the manufacturing and test processes and to maintain close adherence to specifications.

6. Parts must be standarized as much as possible.

7. Good housekeeping practices must be followed at all times and places - contamination is one of the major causes of failure.

Both the aerospace and biomedical equipment industries are engaged in activities characterized by small build rates of the end products - be it a cardiac computer or a spacecraft. High reliability is difficult to 
attain, just as difficult to maintain, and even more difficult to improve. It is hoped that the experience of NASA will in many ways be of value to the biomedical equipment industry and to the medical facilities which must use the equipment to produce improved medical care.

\section{REFERENCES}

1. Hieb, G. E. and Green, H。 L., " $F$ For Medical Electronic Gear, Hospitals Are Not Very Healthy Places, ${ }^{9}$ Electronics, vol.44, no. 3, Feb。1, 1971, pp。54-60。

2: Anon., "Reliability Program Provisions for Aeronautical and Space System Contractors, ${ }^{\natural}$ NASA NHB 5300。4(1A), 1970.

3. Anon., "SERT II Reliability and Quality Assurance Manual," R\&QA Office, NASA Lewis Research Center, Cleveland, Ohio, 1968.

4. Struglia, E. J., "Standards and Specifications Information Sources," Gale Research Company, Detroit, Mich., 1966.

5. Anon., "National Aerospace Standards," National Standards Association, Inc., Washington, D.C. 20005.

6. Anon., "Index of Specifications and Standards, " United States Naval Supply Depot (NSD 103), Philadelphia, Pa. 19120.

7. Bazousky, I., Reliability Theory and Practice, Prentice-Hall, New Jersey, 1961 .

8. Earles, D. R. "Reliability Application and Analysis Guide, " MI-60-54 (Rev. 1), Martin Company, Denver, Colo., 1961.

9. Lalli, V. R., 'Electrical Stress Analysis of a Microthruster Power Conditioner," NASA TM X-1686, 1968.

10. Bagwell, J. W., et al., "Review of SERT II Power Conditioning," NASA TM X-2085, 1971 .

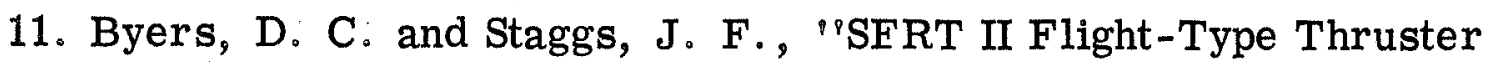
System Performance, ${ }^{i 8}$ NASA TM X-52520, 1969: 
12. Lalli, V。R。, "Ion Engine Subsystem Reliability Procedure," NASA TM X-52055, 1965.

13. Anon., "Patient Safety," Hewlett Packard, AN 718, Waltham, Ma.ss., 1971.

14. Jordan, W. D., Measurement of Risk Currents. Medical Electronics \& Data, Pittsburgh, $\mathrm{Pa}_{\text {, }}$ 1971.

15. Lee, R。H., "Electrical Safety in Industrial Plants," IEEE Spectrum, vol. 8, no. 6, June 1971, p. 51 .

16. Lalli, V。R。, "Reliability Testing and Demonstration Aerospace Problems, ${ }^{\circ 9}$ NASA TM X-67877, 1971.

17. Earles, D.R. and Eddins, M.F。, "Reliability Physics," AVCO Corp., Wilmington, Mass., 1962.

18. Anon., "Quality Assurance Provisions for Inspection Agencies, Space Systems Contractors," NASA NPC 200-1, 2, 1968.

19. Juran, J. M., ed., Quality Control Handbook, McGraw-Hill, New York, 1962.

20. Calabro, S. R. Reliability Principles and Practices, McGraw-Hill, New York, 1962 . 


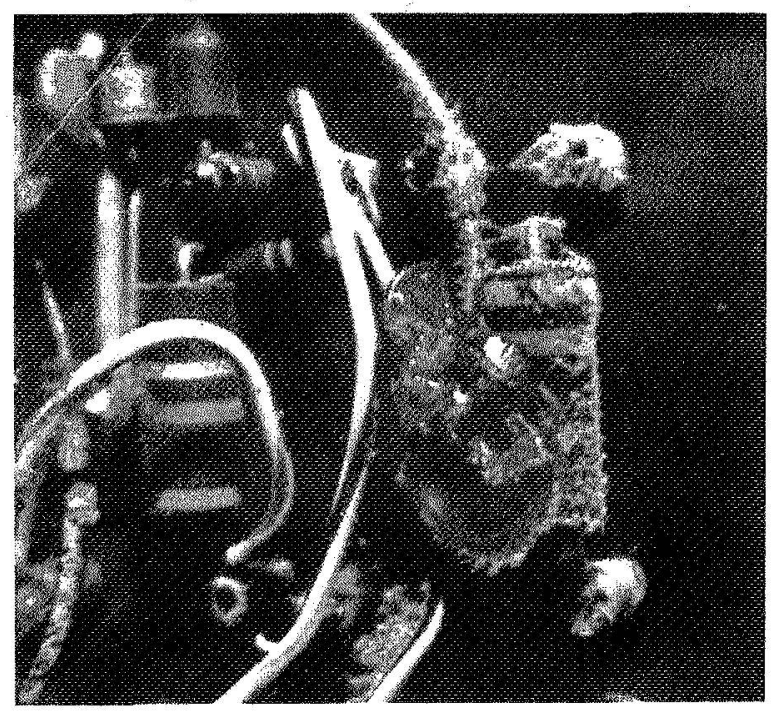

(a) Low quality parts were used in construction.

Figure 1. - Medical electronics gear findings.

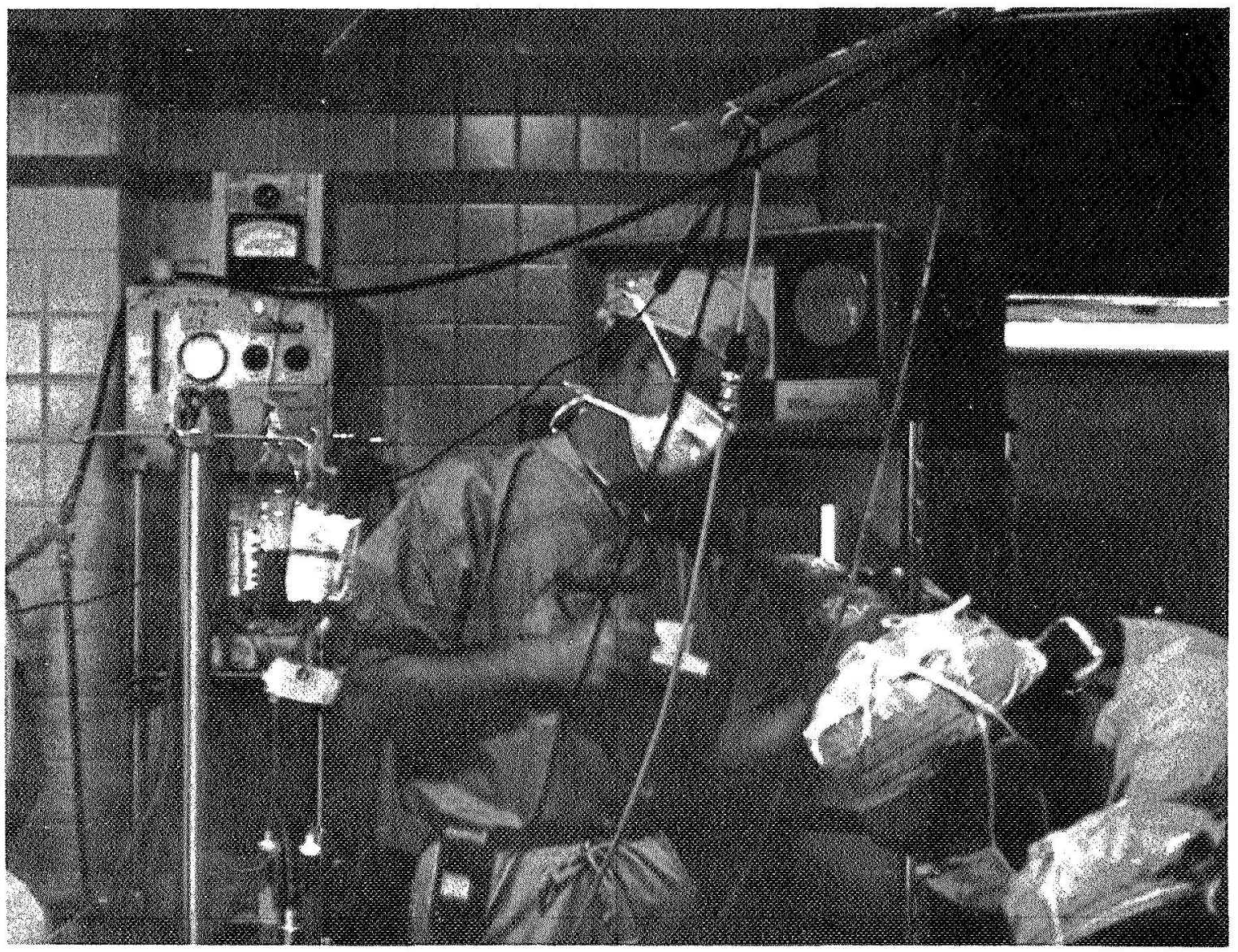

(b) Planning in the placement of equipment was poor.

Figure 1. - Continued. 


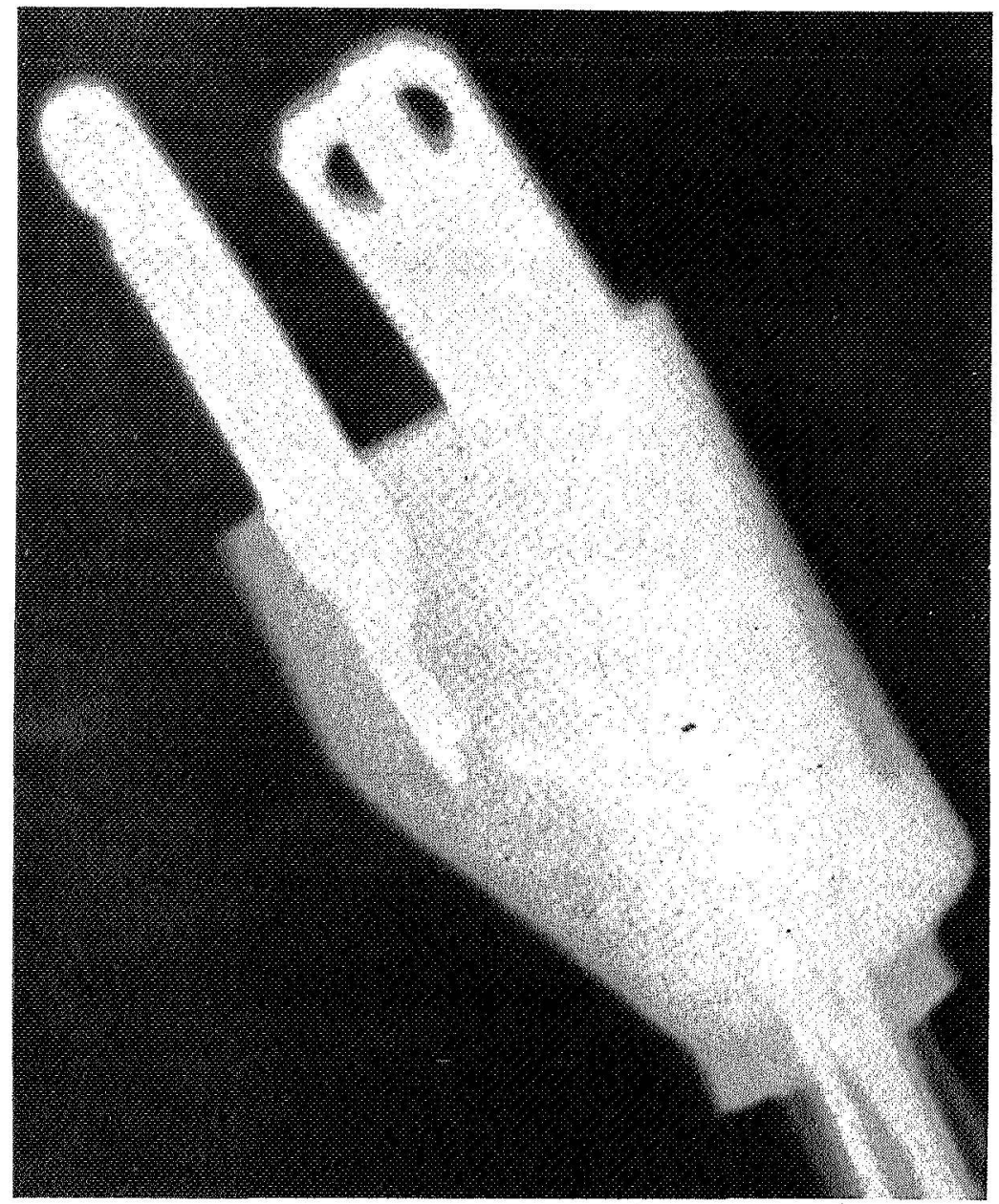

(c) Poor grounding was found in some cases.

Figure 1. - Continued.

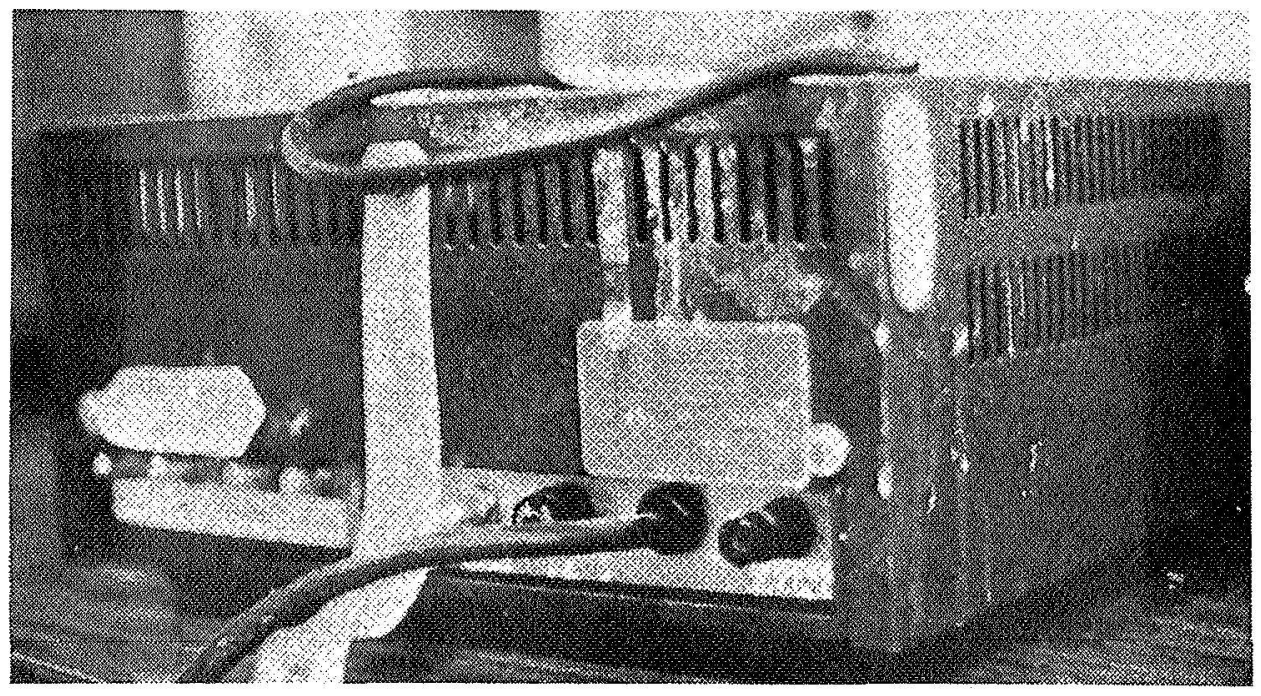

(d) Equipment was not protected adequately from its operating environment.

Figure 1. - Continued. 

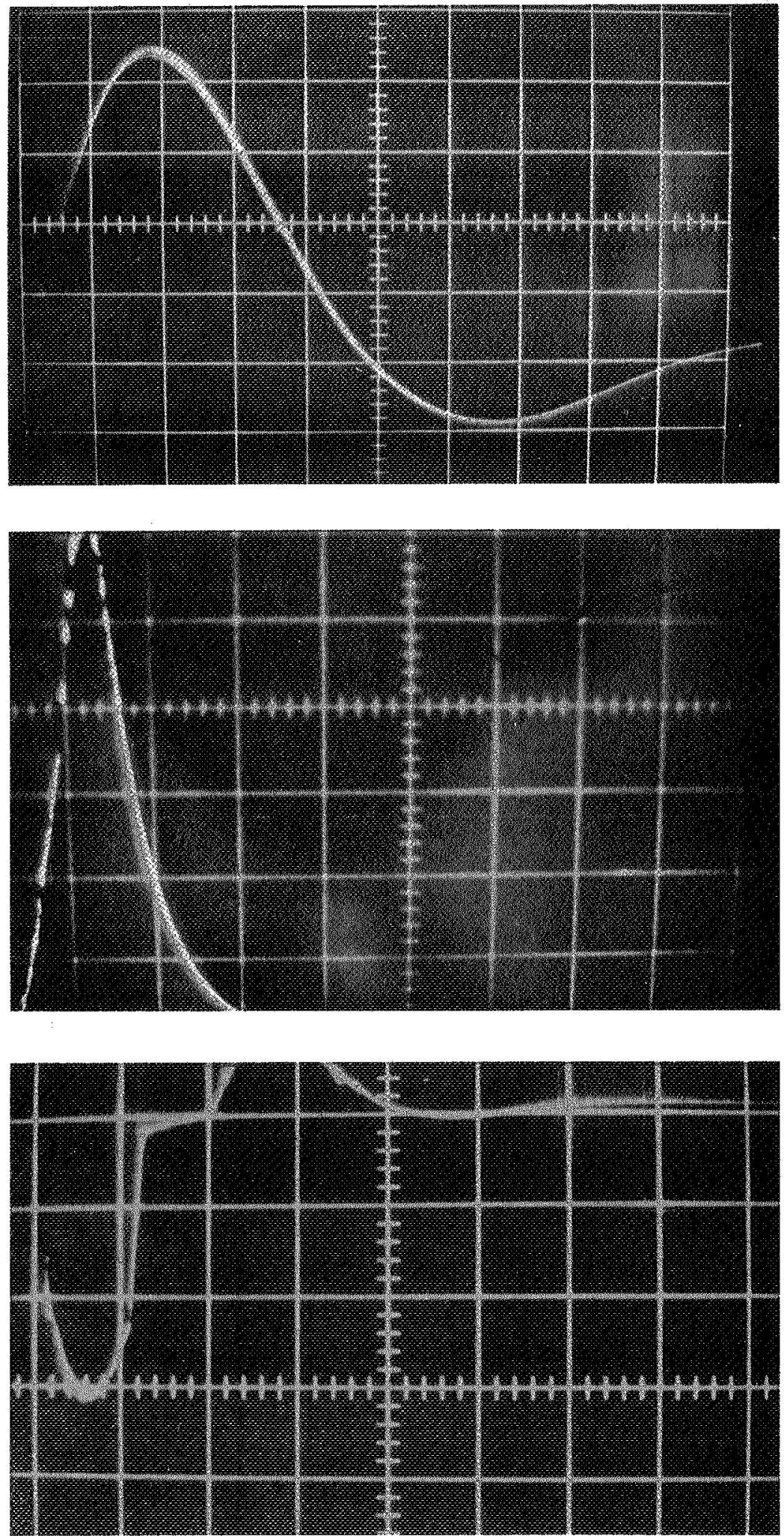

(e) Few defibrillators accurately produce the amount of energy they are supposed to. Figure 1. - Continued. 


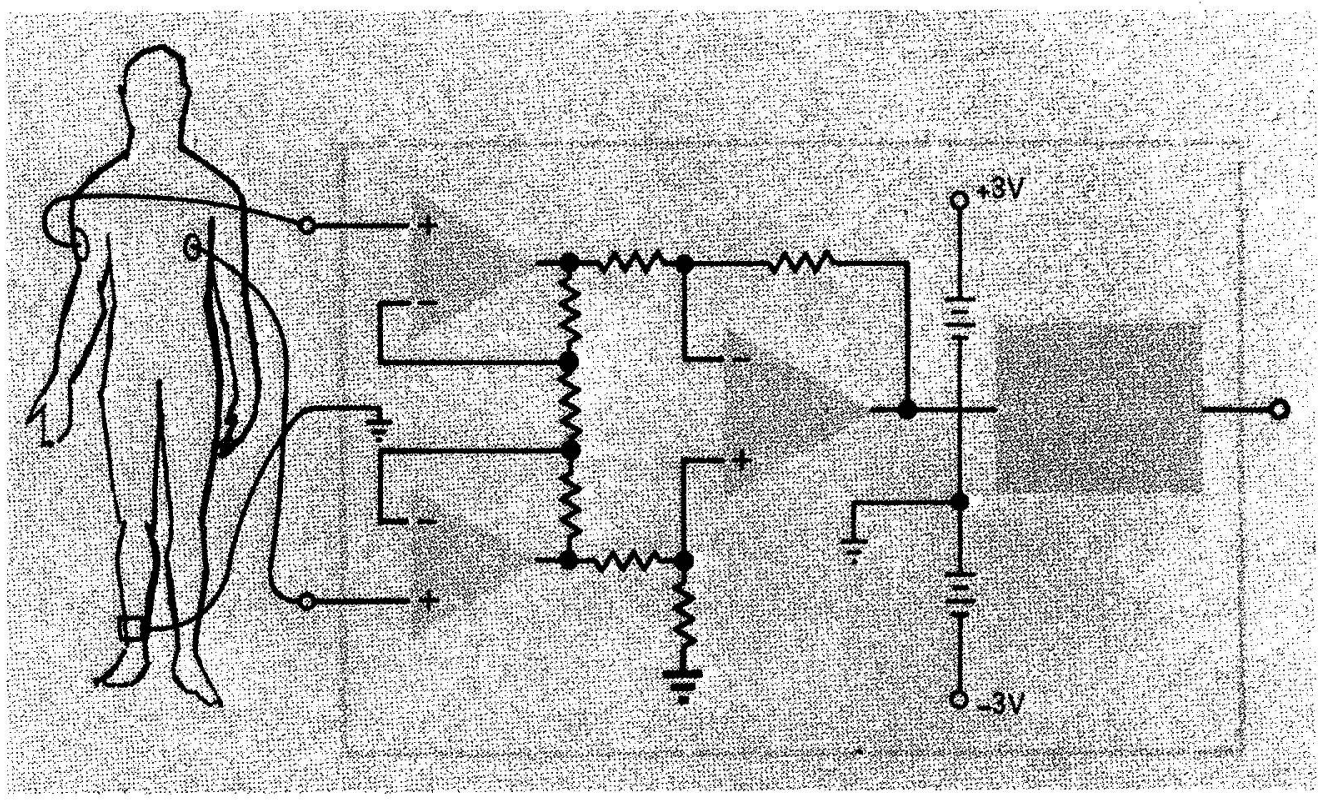

(f) Leakage currents were often in excess of the $10 \mu$, a level which has been recommended by the Veterans Administration and others.

Figure 1. - Concluded.

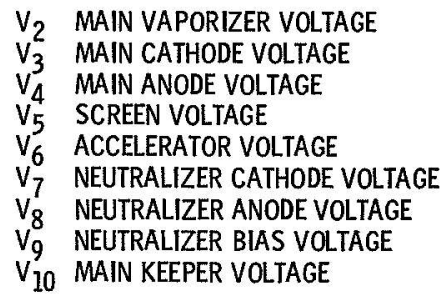

THRUSTER SUB-SYSTEM

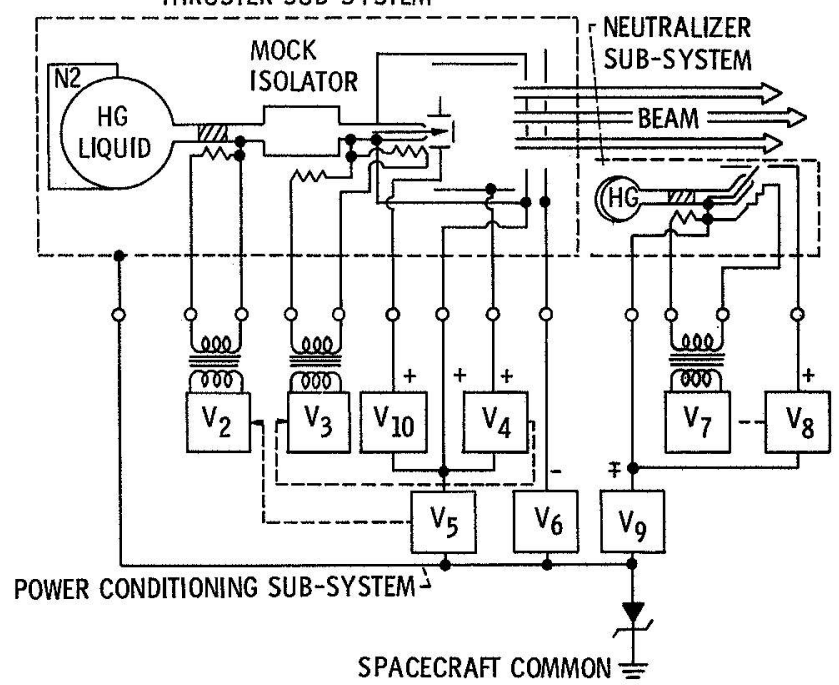

Figure 2. - Thruster -power conditioner block diagram. 

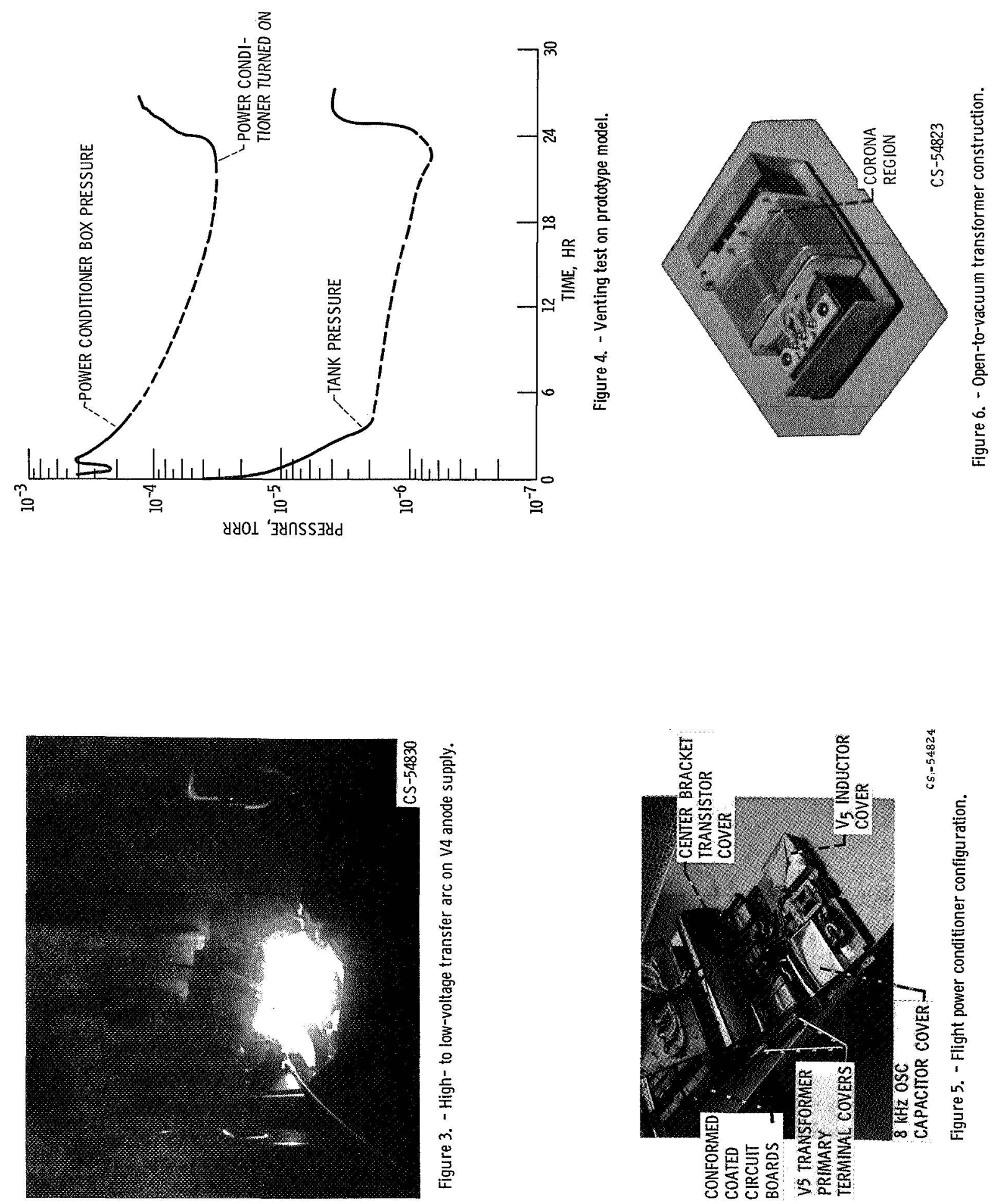


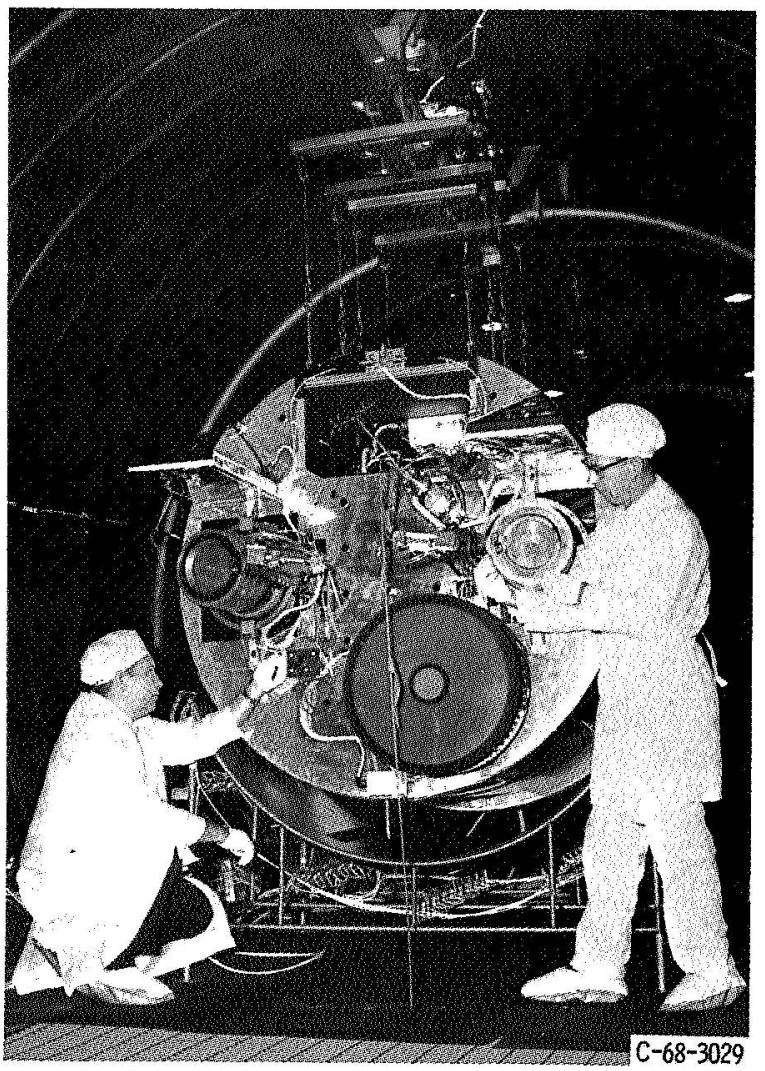

Figure 7. - SERT II spacecraft in operational testing.

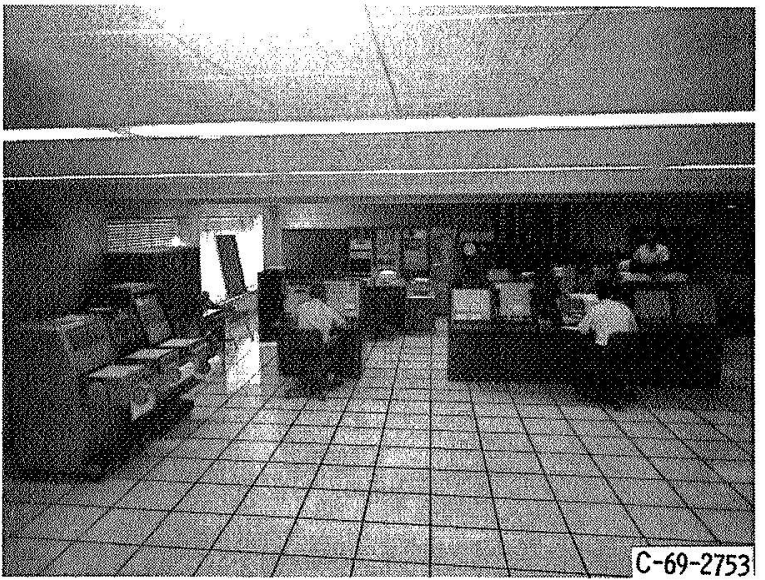

Figure 8. - SERT II flight control center. 